\title{
Pore Structure Characteristics of Taiyuan Formation Shale in Qinshui Basin
}

\author{
Hongyue Duan ${ }^{1,2}$, Wenkai Zhang'2, Xinquan Wang2, Kaizi Jiang2, Tingting Huang3 \\ ${ }^{1}$ School of Resources and Geosciences, China University of Mining and Technology, Xuzhou, China \\ ${ }^{2}$ Shanxi Key Laboratory of Resources, Environment and Disaster Monitoring, Shanxi Coal Geology Geophysical Surveying \\ Exploration Institute, Jinzhong, China \\ ${ }^{3}$ School of Earth and Space Sciences, University of Science and Technology of China, Hefei, China \\ Email: *373267527@qq.com
}

How to cite this paper: Duan, H. Y., Zhang, W. K., Wang, X. Q., Jiang, K. Z., \& Huang, T. T. (2020). Pore Structure Characteristics of Taiyuan Formation Shale in Qinshui Basin. Journal of Geoscience and Environment Protection, 8 , 126-146.

https://doi.org/10.4236/gep.2020.87007

Received: June 5, 2020

Accepted: July 24, 2020

Published: July 27, 2020

Copyright $\odot 2020$ by author(s) and Scientific Research Publishing Inc. This work is licensed under the Creative Commons Attribution International License (CC BY 4.0).

http://creativecommons.org/licenses/by/4.0/

\begin{abstract}
Qinshui Basin is located in the southeast of Shanxi Province, China. Taking the shale of Taiyuan Formation in Qinshui Basin as the research object, the study analyzed the pore size of the shale of Taiyuan formation in detail from micropore to macropore by the methods of mercury injection, liquid nitrogen analysis and combination of liquid nitrogen and mercury injection. The results show that: 1) the visible pores and macropores are poorly developed and distributed unevenly in the shale of Taiyuan formation, and the micropores are well developed in the shale, and there are more open pores in the pore diameter range, and the pore connectivity is good;2) the liquid nitrogen experiment shows that the pores of Taiyuan Shale are relatively developed between $15 \mathrm{~nm}$ and $20 \mathrm{~nm}$, and the formation of hysteresis loop may be caused by some narrow slit pores with similar layered structure; 3 ) the comprehensive analysis of liquid nitrogen and mercury injection experiments shows that the shale of the Taiyuan formation mainly develops micropores, the Mesopores is not developed, the pore volume at $10-100 \mathrm{~nm}$ is more developed than other parts, and the specific surface is mainly contributed by micropores, which can improve the efficiency of shale gas resolution; at the same time, it provides a channel for Shale gas migration, which is beneficial to the development of shale gas.
\end{abstract}

\section{Keywords}

Qinshui Basin, Taiyuan Formation, Shale, Pore Structure, Mercury Intrusion Method, Liquid Nitrogen Method

\section{Introduction}

In recent years, China's environmental problems have become increasingly se- 
rious, especially in the past two years. Environmental problems have a larger impact on people. Natural gas is relatively easy to handle and has little pollution. The research and development of conventional gas in natural gas have been mature, but there are still many problems to be solved in unconventional gas reservoirs. Unconventional gas reservoir is a good supplement to conventional gas reservoir, and shale gas, as an important unconventional natural gas, has become a new hot spot of oil and gas resources exploration and development in the world.

Shale gas refers to the natural gas that accumulates in the source rock mainly by thermal maturation or continuous biological action and the interaction between them. Most of the natural gas occurs on the surface of rock particles and organic matter in an adsorptive state, or Free State exists in the pores and cracks, and a few are dissolved state. Its global resources amount to $456.2 \times 1012 \mathrm{~m}^{3}$, of which China resources amount to $21.5 \times 1012-45 \times 1012 \mathrm{~m}^{3}$ and the median value is $30.7 \times 1012 \mathrm{~m}^{3}$ (Liu et al., 2010). As a very large amount of natural gas resources, the exploration and development of shale gas will be of great significance to the adjustment of China's energy structure (Chen et al., 2012).

There are many key factors affecting the formation of shale gas reservoirs, such as the distribution characteristics of shale reservoirs, TOC content, maturity, pore-fracture characteristics and so on. The pore character of shale is a very important factor, which is of decisive significance to the evaluation of shale gas. Shale gas research in China started late and is still in its infancy. The study on the pore of Shale, especially in the transitional facies of sea and land, has not been well understood yet (Chen, 2013).

This paper takes Taiyuan Formation Shale in Qinshui basin as the research object, analyzes the characteristics of shale pore system, and studies the influence of Shale Reservoir pore system on shale gas accumulation further. It is expected that the research results will be of some reference value to the evaluation of shale gas resources and development prospect in Qinshui Basin (Clarkson et al., 2012).

\section{The Characterization Method of Shale Pore Structure}

In the study of shale pores, there are generally two classification schemes, one is based on the international theory and Applied Chemistry Society of Shale Pores classification scheme, namely micro-pore $(<2 \mathrm{~nm})$, medium pore or meso-pore (2- $50 \mathrm{~nm})$, large pore or macro-pore $(>50 \mathrm{~nm})$. The other is to classify the pore structure into four categories: Large Pore (aperture $>1000 \mathrm{~nm}$ ), medium pore (aperture $1000 \mathrm{~nm}-100 \mathrm{~nm}$ ), transition pore (aperture $100 \mathrm{~nm}-10 \mathrm{~nm}$ ) and Micropore (aperture $<10 \mathrm{~nm}$ ). Considering the specific situation, the pore size measured in the experiment is almost above $2 \mathrm{~nm}$, so we decided to use the latter to study the Taiyuan Group Shale.

At present, there are many methods to study the nanometer-scale pores of Shale, in which the fine pore image structure can be obtained by combining scanning electron microscopy (SEM) with Argon Ion cutaway light technique, however, this method can only be used to determine the pore size distribution of 
statistical methods, its accuracy varies with the representative strength of the sample. Mercury injection method and gas adsorption method can reflect the pore characteristics of shale well. Nitrogen adsorption method can overcome the characteristics of large specific surface area and small pore size of mud shale. According to the pore characteristics of micro-fractures and layered micro-pores, the pore size distribution is calculated by using $\mathrm{BJH}$ principle, it can reflect the distribution of micro-pore and small-pore accurately: Mercury injection method can measure the middle-pore and big-pore accurately, and can make up for the deficiency of nitrogen adsorption method, in this paper, the MESOPORES and macropores in shale are analyzed accurately (Liu et al., 2010; Zhao et al., 2011).

According to the specific situation of this study, we decided to use mercury injection method and liquid nitrogen method and liquid nitrogen and mercury injection method to analyze the pore size of Taiyuan group shale from micro-pore to large pore. According to the experimental characteristics of low-temperature nitrogen adsorption method and mercury injection method, the optimal pore section is selected to analyze when liquid nitrogen is combined with mercury injection. For the low temperature nitrogen method, the part less than $50 \mathrm{~nm}$ was used, and for the mercury injection method, the part larger than $50 \mathrm{~nm}$ was used (Curtis, 2012; Gu et al., 2011). In addition, because the pore of mercury injection test needs to be broken to $2-3 \mathrm{~nm}$, it will bring some pore cracks artificially, which will lead to deviation of measurement. According to the past experience, the pore size of mercury immersed in mercury injection test under low pressure will be eliminated if the pore size is larger than $100,000 \mathrm{~nm}$, analysis and measurement results show that the pore size is less than 100,000 $\mathrm{nm}$, which can characterize the pore structure more accurately (Jia et al., 2012; Ma et al., 2013).

\section{Mercury Intrusion Method}

\subsection{The Experimental Principle of Mercury Intrusion Method}

Mercury injection test is one of the commonly used methods to measure the distribution of pore throat. Mercury intrusion method can reflect pore size and pore volume distribution of shale well, but its measuring range is more than 3 $\mathrm{nm}$, some are $3.75 \mathrm{~nm}$, so it cannot describe pore size less than $3 \mathrm{~nm}$, and it is not as accurate as liquid nitrogen in the range of $3-50 \mathrm{~nm}$, but on the whole, it's pretty reliable. The principle is: When Mercury is injected into shale by mercury injection method, capillary resistance will be generated due to the existence of capillarity, but it is the pore throat size, not the pore size, that controls mercury entering the pore, the size of the pore throat determines the size of the resistance, the smaller the pore throat, the greater the resistance. Therefore, the pore throat size distribution can be determined by the pressure value. At the same time, the pore volume of a certain size of pore throat is studied according to the amount of mercury input in different stages (Li et al., 2009; Liu et al., 1998). 
The size of the throat can be determined by means of a CAPILLARY TUBE:

$$
P_{c}=\frac{2 \sigma \cos \theta}{r}
$$

Under: $P_{c}$-Capillary pressure, dyne $\mathrm{CM}^{2}$;

$\sigma$-Assume tension, dyne $\mathrm{CM}^{2}$;

$\theta$-Wetting contact angle of Mercury, ( );

$r$-Laryngeal radius, $\mathrm{CM}$.

$P_{c}$ was measured by $\mathrm{kg} / \mathrm{cm}^{2}, \mathrm{R}$ was measured by $\mu \mathrm{m}, \theta$ was $146^{\circ}, \sigma$ was 480 $\mathrm{d} / \mathrm{cm}^{2}, \mathrm{Pc}$ was $7.5 / \mathrm{R}$. Therefore, mercury injection method can be used to determine the pore size of the various throat in the pore system of porous shale, and its corresponding pore volume $(\mathrm{Pu}, 2008)$.

\subsection{The Characterization of Pore Characteristics of Taiyuan Formation Shale by Mercury Intrusion Method}

The Pore in shale is composed of effective pore and isolated pore, the former is the pore that gas and liquid can enter, which can provide space for the storage of shale gas, and the latter is the pore that gas and liquid cannot enter, which is called "Dead Pore" and is completely closed, however, due to the fragmentation of samples in mercury intrusion experiment, the results may be affected to some extent, and the instrument used in this experiment is: Autopore IV 9500v1.09 automatic mercury intrusion instrument, the lower limit of aperture is $3 \mathrm{~nm}$, therefore, it can only reflect the pore characteristics of shale above $3 \mathrm{~nm}$, so it has some limitations.

1) Characterization of Shale porosity by mercury injection method

Shale has low porosity and is a typical low porosity and low permeability reservoir. However, porosity is a prerequisite for shale gas enrichment, so a certain porosity is a necessary condition for shale gas accumulation. But the mercury injection test can only show the pore of shale above $3 \mathrm{~nm}$, so in fact, the pore of shale is larger than that measured by mercury injection, so other methods are needed. As shown in Table 1, mercury injection test shows that the porosity of Taiyuan formation shale is between $1.39 \%$ and $3.58 \%$, with an average of $2.20 \%$.

Figure 1 shows that the correlation between Clay Minerals and porosity is good, and the porosity increases with the decrease of clay minerals. Figure 2 shows that TOC has a poor correlation with porosity, but three sets of data show that porosity increases with TOC. It indicates that the organic matter in the shale of the Taiyuan formation in the Qinshui basin provides more porosity.

2) Characterization of Pore size, Pore volume and pore specific surface area distribution by mercury intrusion porosimetry

According to Figure 3, the relationship between pore size and phase mercury

Table 1. Statistic table of shale porosity of upper Taiyuan formation in Qinshui basin.

\begin{tabular}{cccccccc}
\hline SAMPLE NUMBER & HSM-29 & HSM-37 & HSM-58 & SH-45 & SH-35 & SH-20 & MEAN VALUE \\
\hline POROSITY/\% & 2.13 & 1.86 & 1.48 & 3.58 & 1.39 & 2.74 & 2.20 \\
\hline
\end{tabular}




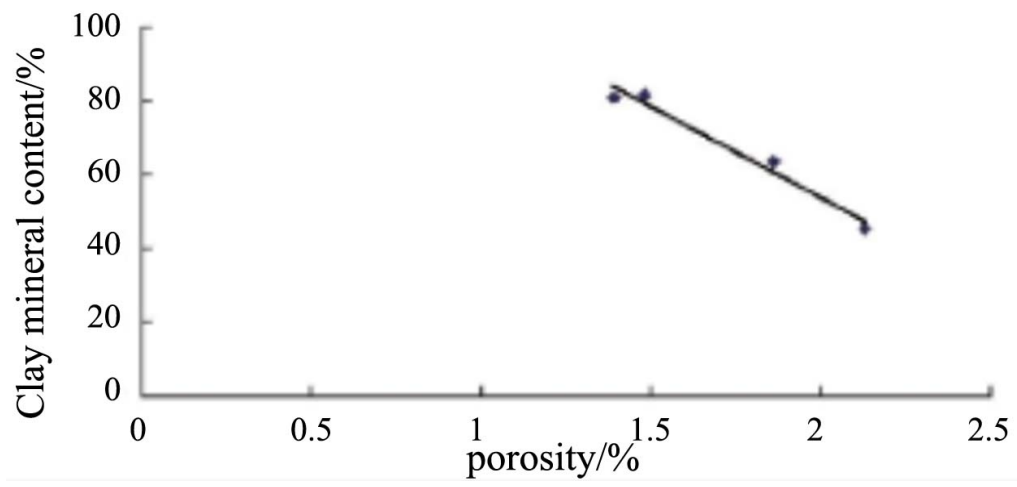

Figure 1. Clay mineral-porosity Diagram 2 to c-porosity diagram.

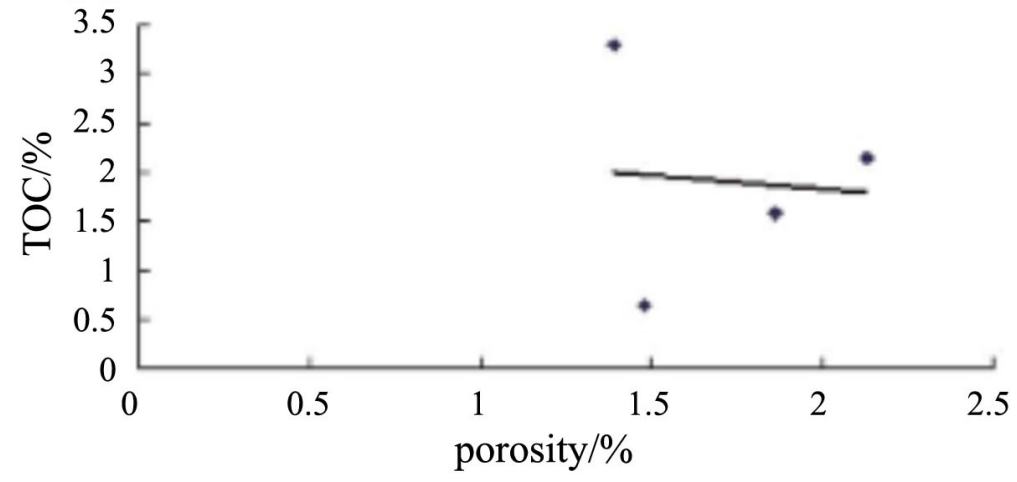

Figure 2. Relationship between TOC and porosity.

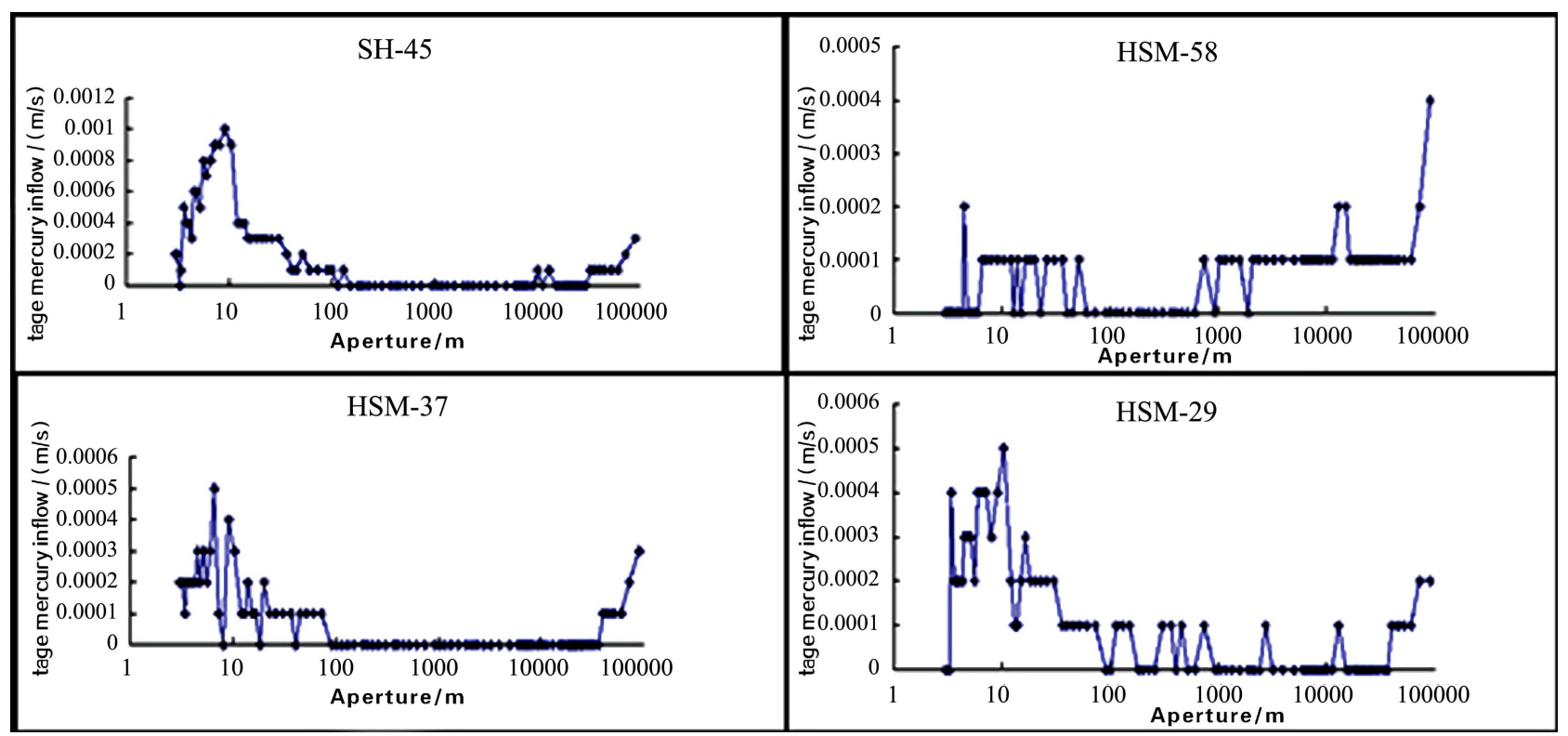

Figure 3. Relationship between Pore size and phase mercury feed.

input is bimodal, which indicates that the pore size of Taiyuan Formation Shale is only distributed in two regions. The double peaks of HSM-27 and SH-45 are the most obvious, and the pore size distribution is between $3-100 \mathrm{~nm}$ and 40,000 - 10,000 nm. HSM-29 and HSM-58 are also bimodal, but some of the 
pores in HSM-29 occupy 7\% of all the pores. HSM-58 is different. It is mainly a micropore and macropore with no development of Mesopores, but the pores mainly develop between $3-100 \mathrm{~nm}$ and $1000-10,000 \mathrm{~nm}$. The results show that the shale pores in Taiyuan formation are mainly composed of micro-pores and macro-pores, which are mainly distributed between 3 - $100 \mathrm{~nm}$ and 40,000 $10,000 \mathrm{~nm}$. The Pore volume distribution is between 0.0068 and $0.017 \mathrm{ml} / \mathrm{g}$, with an average of $0.0103 \mathrm{ml} / \mathrm{g}$. The Pore volume between $10 \mathrm{~nm}$ and $100 \mathrm{~nm} \mathrm{ac-}$ counts for more than $50 \%$, and the volume below $10 \mathrm{~nm}$ accounts for more than $30 \%$, the results show that the shale pores of Taiyuan formation are mainly composed of micropores.

According to Figure 4, it can be seen that the bulk of the specific surface area of shale pores is between $3-10 \mathrm{~nm}$, accounting for more than $98 \%$ according to statistics. Therefore, almost all the adsorbed gas in shale comes from micro-pores, which shows the importance of micro-pores in shale.

3) Characteristics of mercury intrusion and mercury ejection curve

Mercury injection test results show that the forward/backward curve can reflect the characteristics of shale pore. Figure 5 shows the phase entry/Mercury curves under different pressures. The following characteristics can be seen from the diagram:

a) the mercury intake curve is bimodal with multiple zero mercury intake between 10 - 40,000 PSI.

b) when HSM-58 is at low pressure, there are two peaks in the input-output curve.

c) the mercury uptake of HSM-29, HSM-58 and SH-20 was significantly higher than that of the other three samples between 10 - 1000 PSI.

d) the mercury contents of HSM-29, HSM-37, HSM-58, SH-45 and SH-35 under low pressure are smaller than those of $\mathrm{SH}-20$, indicating that the macropores of the former are more developed than those of the latter.

e) the first peak of HSM-58 and SH-35 was larger than the second one, which

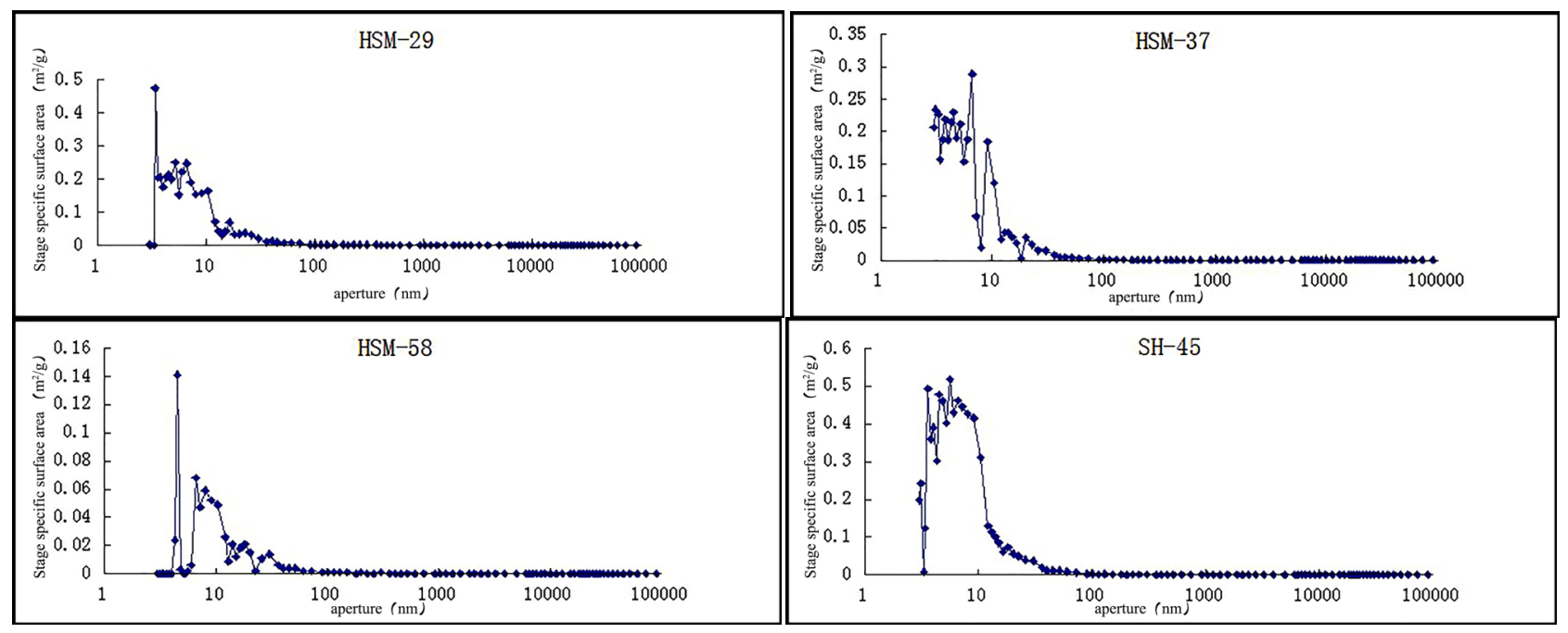

Figure 4. Relationship between aperture and specific surface area. 


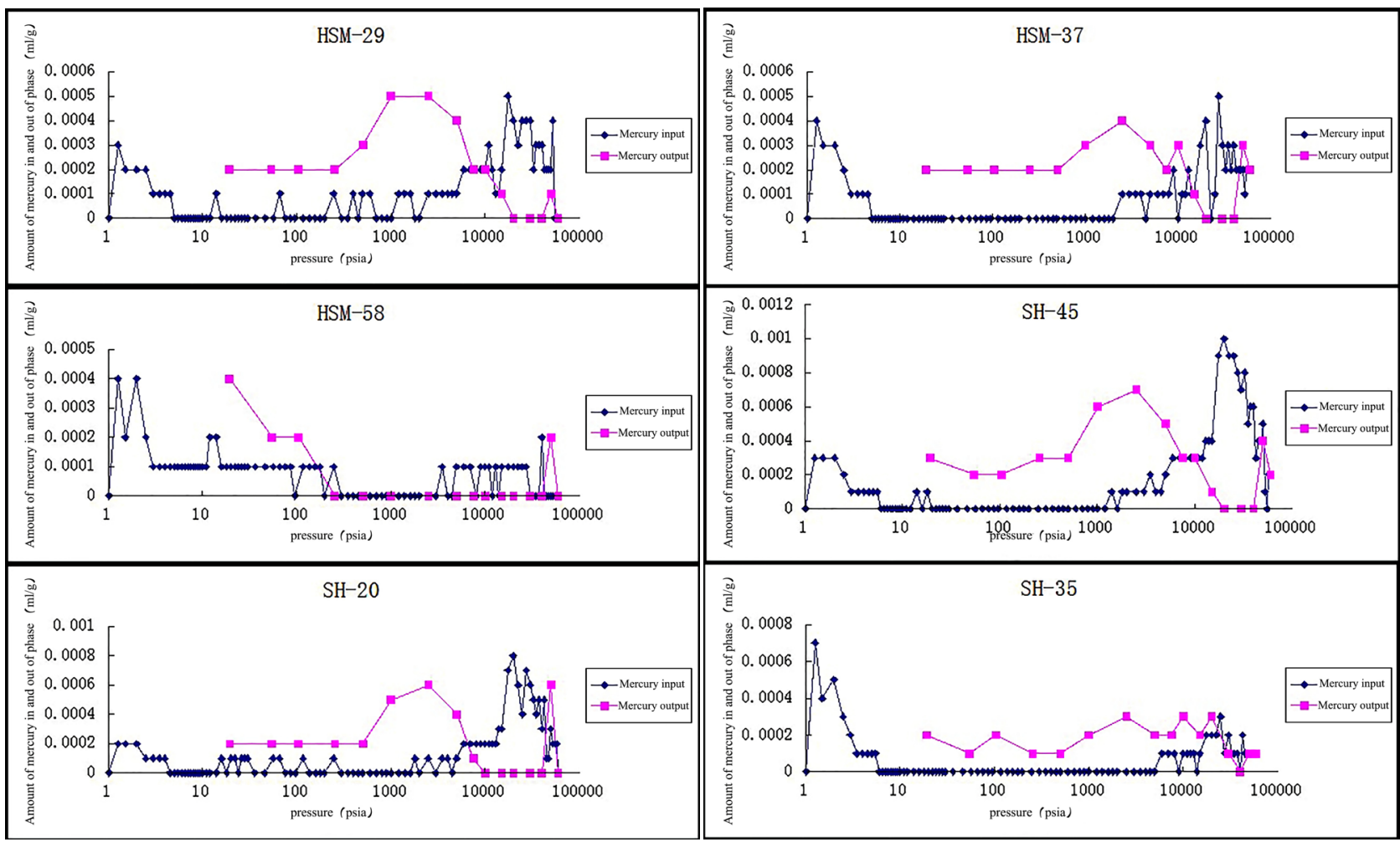

Figure 5. Mercury volume diagram of shale at different pressures during mercury introduction and mercury withdrawal.

indicated that the macropore was more developed than the middle and small pore.

f) the mercury ejection curve shows a small peak at pressure 100,000 PSI, then increases gradually, and then drops to a more stable value.

g) the HSM-58 mercury ejection curve is abnormal compared with other mercury ejection curves. The mercury ejection is basically zero at high pressure, and at 250 PSI, the amount of mercury ejection increases with the decrease of pressure.

Under low pressure, mercury can only penetrate into the visible pores and macropores. When the visible pores and macropores of a certain pore size are filled with mercury, the pressure continues to increase, and mercury gradually penetrates into the smaller pores of some macropores in shale, therefore, there are few multi-peaks in the shale under low pressure, only two peaks appear in HSM-58, which shows that the pore size distribution in the macropore is basically composed of two major parts, showing two stages, so there are two peaks. The results show that the pores and macropores are not well developed and distributed unevenly in the shale of Taiyuan formation. When the mercury pressure increased to 40,000 PSI, the mercury intrusion gradually increased and then decreased, indicating that the mercury gradually penetrated into the pores of the pore throat which were smaller and more difficult to enter after the pressure increased to 40,000 PSI.

Figure 6 shows the cumulative mercury volumes in shale under different 

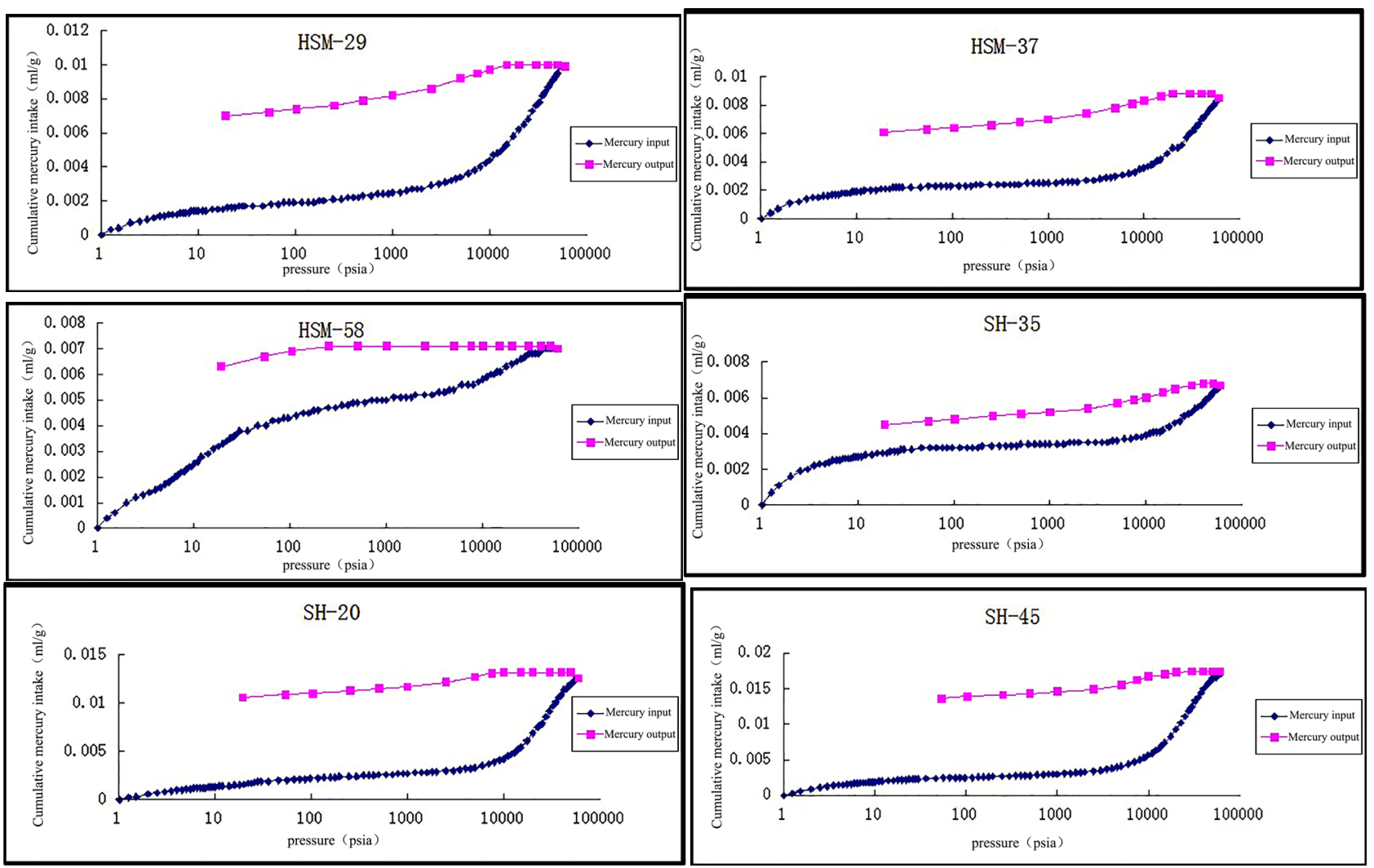

Figure 6. Mercury-entering and mercury-withdrawing cumulative mercury volume maps for shale under different pressures.

pressures. The following characteristics can be seen by comparing the curves in Figure 6:

a) the mercury injection curves increased gradually below 10 PSI, from 10 to 10,000 PSI, and then gradually increased after 10,000 PSI, indicating that the distribution of pores in the Taiyuan Formation Shale is concentrated, which is mainly composed of micropores and macropores.

b) the mercury ejection curve is flat, the pore lag ring of mercury injection curve is wide, the mercury ejection curve is convex and Concave, and the volume difference of mercury advance and retreat is large, which indicates that there are more open pores in the pore diameter range of mercury injection test, and the pore connectivity is good.

c) the curve below 100 PSI of HSM-58 is steeper than that of other samples, indicating a certain amount of mercury input in a lower pressure range, indicating that HSM-58 has more macropores than other samples.

\section{Nitrogen Adsorption at Low Temperature}

\subsection{Experimental Principle of Nitrogen Adsorption at Low Temperature}

The experiment of nitrogen adsorption at low temperature is also one of the common methods to measure the distribution of pore throat. The principle is: using $\mathrm{N} 2$ as the adsorbing gas, under the condition of constant temperature, the 
partial pressure of the gas is gradually increased, at the same time measuring the adsorption amount of the shale sample to N2, so that the shale sample can be obtained from the partial pressure and the adsorption amount of the Sorption isotherm; On the contrary, the desorption isotherms are made by decreasing the partial pressure and measuring the desorption amount at the same time. The Pore volume of shale is calculated from the amount of $\mathrm{N} 2$ adsorbed at its boiling point. At the N2 boiling point, the smaller pores in the shale will be filled with the liquefied N2 due to the condensation of the microtubules when the relative pressure is near 1 (Wang, 2005; Tian et al., 2012). According to the principle of capillary condensation, the smaller the pore diameter, the smaller the partial pressure needed for gas condensation at the boiling point temperature, and the volume of N2 liquid adsorbed at different partial pressures corresponds to the volume of the corresponding pore size, therefore, pore volume distribution can be used to determine the pore size distribution. The BET equation can be used to calculate the specific surface area and the $\mathrm{BJH}$ equation to calculate the volume distribution (Wang, 2012; Jiang et al., 2012).

\subsection{Characterization of Shale Porosity in Taiyuan Formation by Low Temperature Nitrogen Adsorption Method}

The determination of Shale porosity by low temperature nitrogen adsorption method is generally below $100 \mathrm{~nm}$, and below $100 \mathrm{~nm}$ is also the stage of shale pore development, which is representative, but the pore distribution of different shale is different, therefore, the low temperature liquid nitrogen adsorption hair also has certain limitations (Wang et al., 1998).

1) characteristics of ISOTHERMAL adsorption curve of nitrogen adsorption at low temperature

The ISOTHERMAL adsorption curves of IPUAC solid adsorbents are divided into six categories, as shown in Figure 7. The shapes of each isotherm reflect the
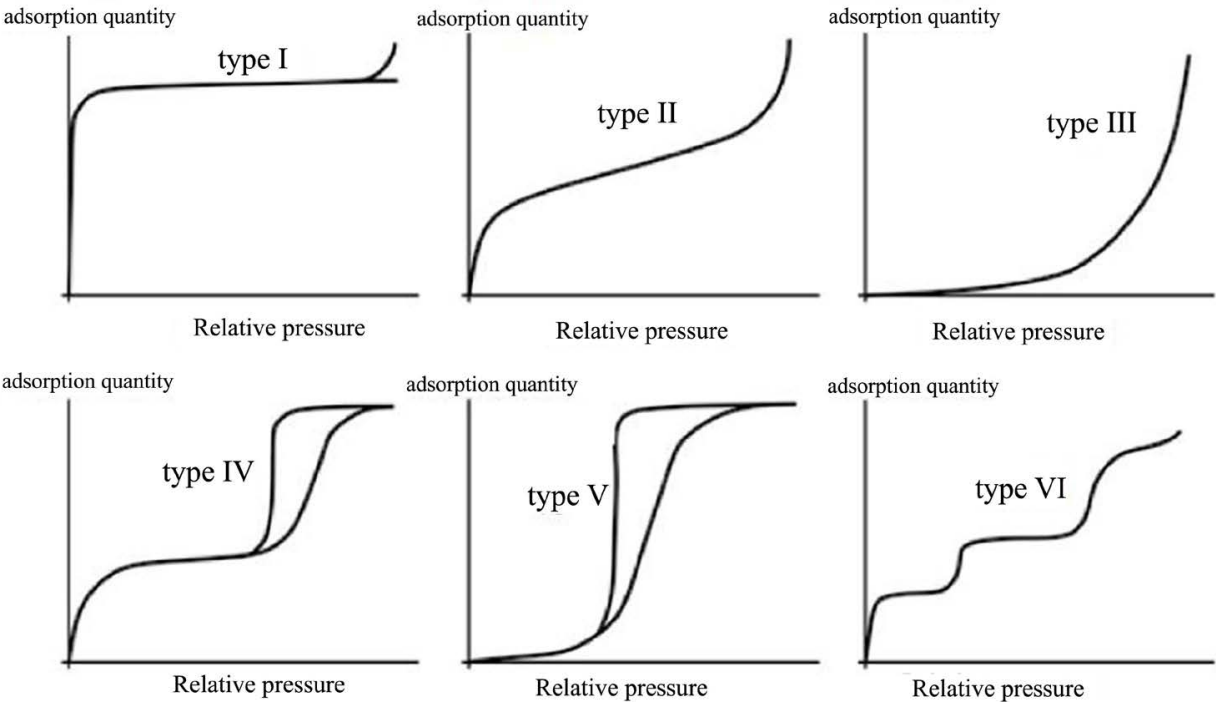

Figure 7. Class 6 ISOTHERMAL adsorption lines according to IPUAC. 
size and shape of the pores of the adsorbents and the interactions between the adsorbents and the adsorbents. Therefore, the shape of isothermal adsorption curve can be used to infer the characteristics of adsorbent pores.

The type I isothermal adsorption curve is called Langmuir isotherm, which corresponds to the Langmuir single-layer adsorption process. The turning point of the platform corresponds to the full filling of the pores of the adsorbent. Microporous Silica, Zeolite, carbon molecules and so on will appear this isotherm (Xie et al., 2006). When the ISOTHERMS are close to the saturated vapor pressure, the adsorption will take place in the gap between the particles, and the ISOTHERMS will rise rapidly.

Class II ISOTHERMS: s-type isotherms corresponding to a single, multilayered reversible adsorption process that occurs free on multiple empty surfaces or macroporous solids (Yang et al., 2013). The inflection point B at P/Po is the first steep part of the ISOTHERM, which means that the monolayer is saturated. With the increase of pressure, multi-layer adsorption is formed, and the number of adsorption layers is infinite at saturated vapor pressure. Which means it has a solid size limit of five. The upward and downward convex curves at P/Po indicate the strength of the interaction between the adsorbents and adsorbents (Cui et al., 2012).

Class III ISOTHERMS: The shape is convex downward in the whole pressure range, and the curve does not have inflection point $B$. This linearity occurs when a multimolecular layer occurs on the hydrophobic surface, or when the adsorption interaction between the adsorbent and the adsorbate is less than that between the adsorbate (Yang et al., 2013). In the low pressure area, the adsorption amount is less, and there is no point $\mathrm{B}$, which indicates that the interaction between adsorbent and adsorbate is rather weak. With the increase of the relative pressure, the adsorption amount is more and more, which means there is a hole filling (Yu, 2013).

Class IV ISOTHERMS: convex upward on P/Po Curves, similar to type II isotherms. In the higher P/Po Region, capillary condensation of adsorbate took place and the ISOTHERM increased rapidly. When all the pores are coalesced, the adsorption takes place only on the outer surface, but the outer surface area is much smaller than the inner surface area, and the primary curve is flat. When $\mathrm{P} / \mathrm{Po}$ was close to 1 , the adsorption on the macropore increased. In addition, due to the capillary condensation, a hysteresis phenomenon can be observed in this region, that is, the desorption isotherm does not coincide with the Sorption isotherm, and the desorption isotherm is over the Sorption isotherm, resulting in an adsorption hysteresis loop. The adsorption hysteresis is related to the shape and size of the pore, so the size and distribution of the pore can be known by analyzing the adsorption isotherm.

The mechanism of physical adsorption corresponding to the SORPTION ISOTHERM OF TYPE IV: (Figure 8).

In the first stage, monolayer adsorption was formed, and the inflection point $B$ indicated the saturated adsorption capacity of monolayer

Second stage: Start Multi-layer Adsorption; 


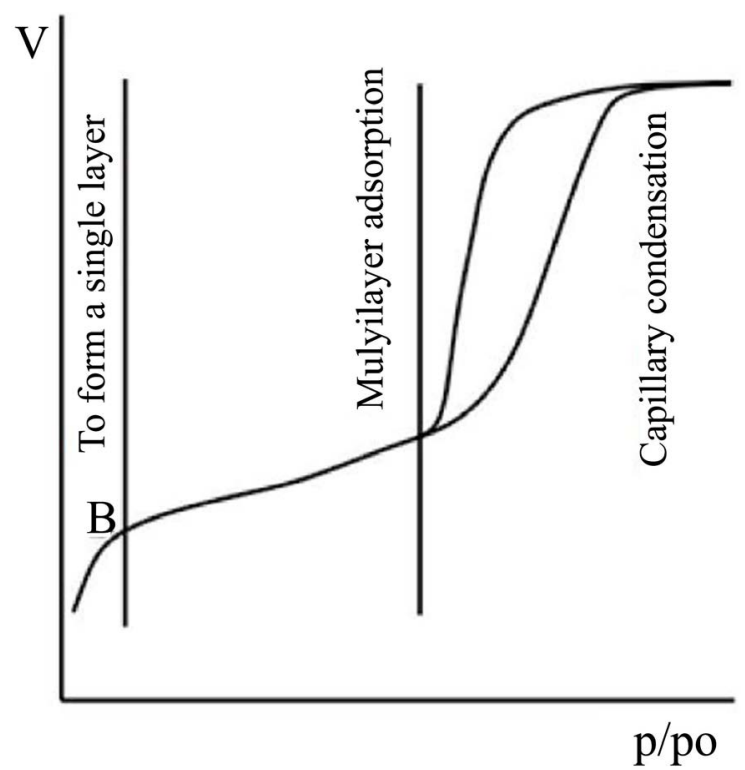

Figure 8. IV Type Sorption isotherm corresponding to the physical adsorption mechanism.

The third stage: capillary condensation, in which the starting point of the hysteresis ring means that the smallest capillary begins to coalesce, and the ending point of the hysteresis ring means that the largest pore is filled with the condensate;

The presence of a plateau after the lag ring indicates that the whole system is filled with condensed liquid and the adsorption capacity is no longer increased, which also means that there is a certain upper limit for the holes in the system.

Class V ISOTHERMS: These ISOTHERMS are rare and difficult to interpret. Although they reflect the weak interaction between the adsorbent and the Adsorbate, they exhibit pore filling in the high pressure region. Sometimes there are capillary condensation and hysteresis loops in the higher P/Po Region.

VI TYPE ISOTHERMS: called step type ISOTHERMS, this type of isotherms is more specific, reflecting the solid is uniform, multi-layer adsorption results on the surface. In fact, the solid surface is very difficult to be uniform, it is difficult to meet this situation.

According to Figure 9, the six ISOTHERMAL adsorption curves in the study area show that:

a) the curve of adsorption and desorption obtained is between II and IV, slightly upward at first, then slowly rising, rising rapidly after 0.9 , but the B point is not obvious, it shows that the interaction between adsorbents and adsorbents is relatively weak.

b) the curve is still upward when the relative pressure is close to 1 , and there is no gentle section in the high pressure region, which shows that the number of adsorbed layers is infinite and the pore size of solid is unlimited when the saturated vapor pressure is near 1 , there are some middle and big holes in the sample. 

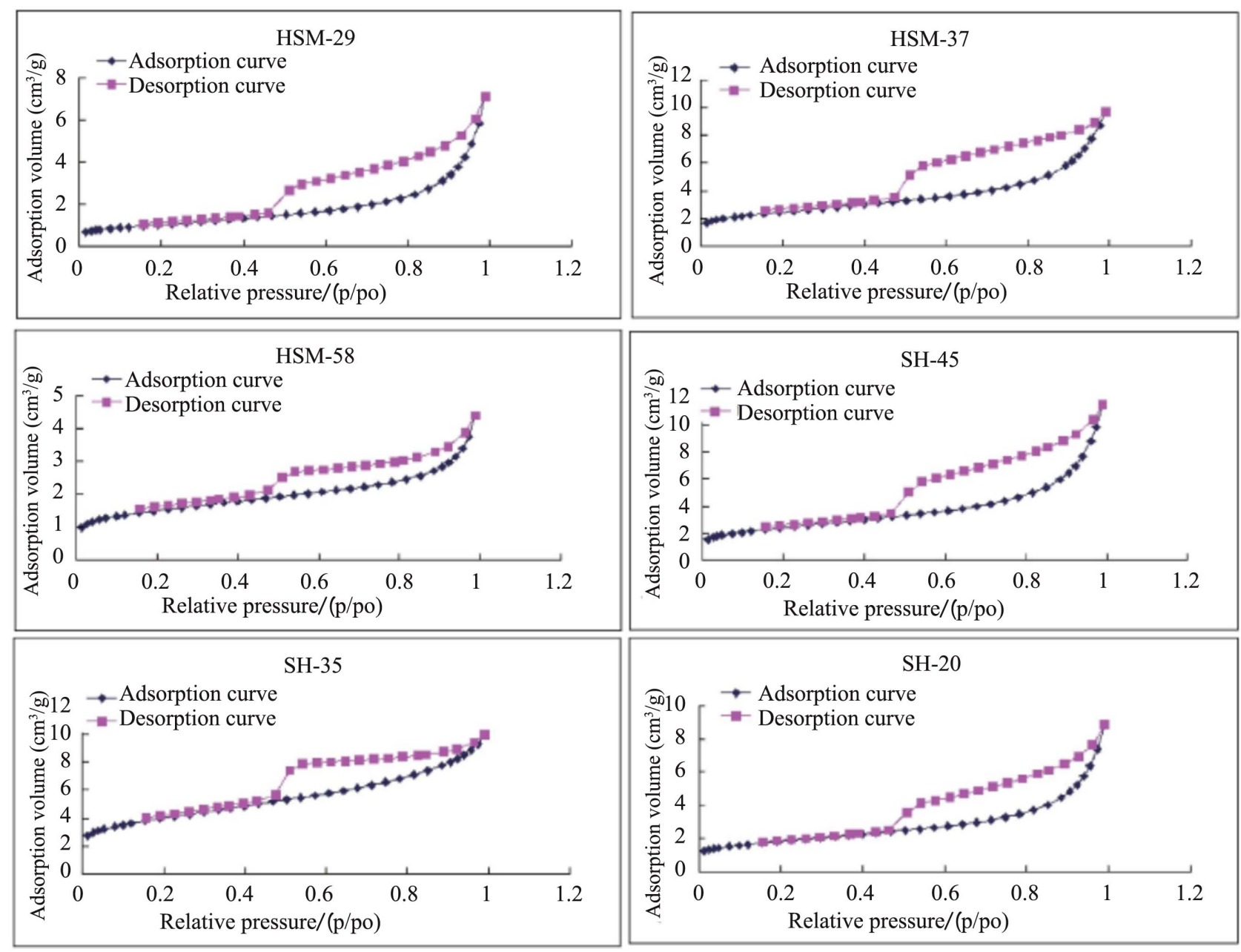

Figure 9. Experimental adsorption/desorption loop diagram of liquid nitrogen.

c) The adsorption curves of the six samples coincide almost below 0.5 and have a good linear relationship. When above 0.5 , they do not coincide, that is to say, they all have hysteresis loops and similar shape. The starting point of the hysteresis loop is about $0.5 \mathrm{p} / \mathrm{Po}$, which indicates that capillary condensation occurs when $\mathrm{P} / \mathrm{Po}$ is about 0.5 .

d) The hysteresis loop of the sample is similar to that of the H4 type, which indicates that the formation of the hysteresis loop may be caused by some narrow slit holes with similar layered structure.

2) Characterization of Pore volume and specific surface area of Taiyuan Formation Shale by low temperature nitrogen adsorption.

Figure 10 shows the relationship between Pore volume and pore size of the Taiyuan Group Shale stage. The Pore volume increases generally with the increase of pore size, and a peak appears in the part between $15 \mathrm{~nm}$ and $20 \mathrm{~nm}$, the results showed that the pores between $15 \mathrm{~nm}$ and $20 \mathrm{~nm}$ were relatively well developed. Generally speaking, the pores of Taiyuan Group Shale are all developed between $2-100 \mathrm{~nm}$, but mainly between $2-50 \mathrm{~nm}$, because the liquid nitrogen method can only measure above $2 \mathrm{~nm}$, but according to the research, the pores 


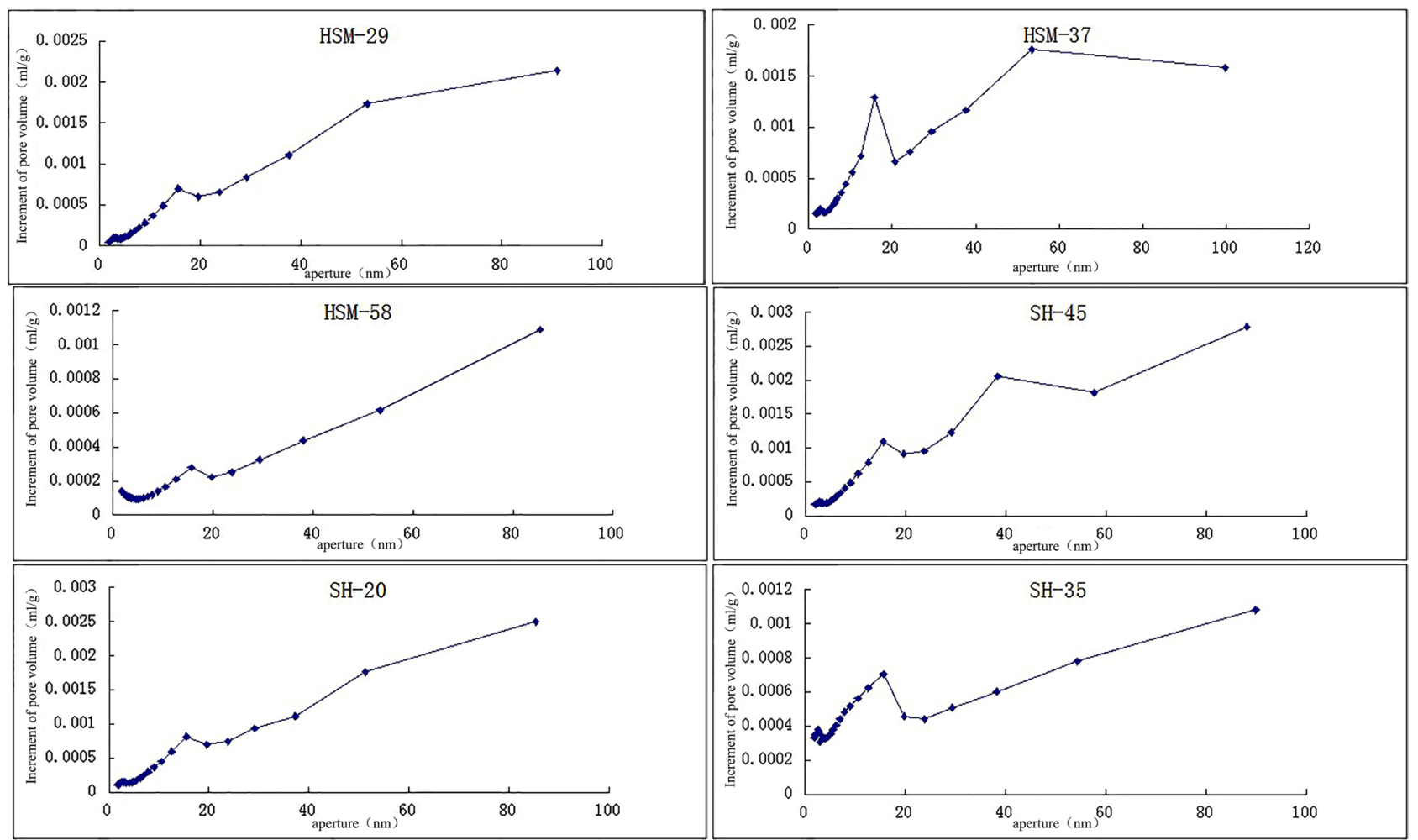

Figure 10. Diagram of experimental pore volume and pore diameter of liquid nitrogen.

below $2 \mathrm{~nm}$ in the shale also contribute to the pores of the shale, further research is needed.

Figure 11 shows the relationship between specific surface area and pore size of Taiyuan Formation Shale stage. HSM-58 and SH-45 are the same type, the specific surface area mainly develops below $10 \mathrm{~nm}, 90 \%$ below $10 \mathrm{~nm}$ and almost all below $50 \mathrm{~nm}$, which shows the contribution of micropores in shale to the specific surface area. HSM-29, HSM-37, SH-35 and SH-20 are the same type. The specific surface area decreases as the pore size increases, but a peak appears between 15 and 20, indicating that the pores are more developed at this stage, which is consistent with Figures 4-10.

\section{Combination Analysis of Low Temperature Liquid Nitrogen Method and Mercury Injection Method}

The Pore structures of Taiyuan group shale were analyzed by connecting the experimental data of Mercury injection with the experimental data of $50-100,000$ $\mathrm{nm}$ and liquid nitrogen with the experimental data of less than $50 \mathrm{~nm}$. The pore volumes of Micropore, transition pore, Middle Pore and large pore are denoted by V1, V2, V3 and V4 respectively, and the total pore volume is denoted by Vt.

1) Characterization of Pore volume of Taiyuan Formation Shale by low temperature nitrogen method and mercury injection method

As can be seen from Table 2 and Figure 12, the distribution of pore volume 


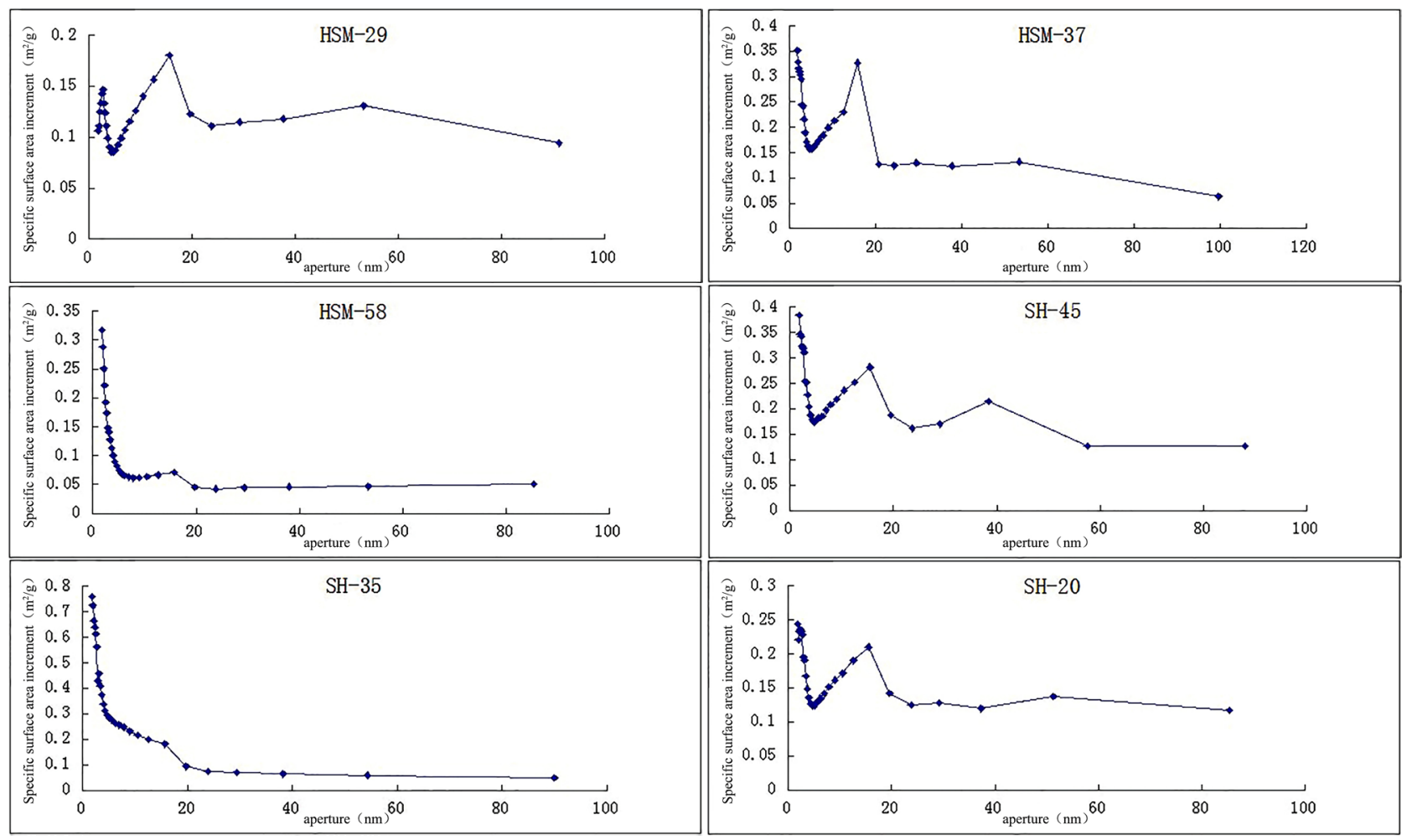

Figure 11. Relationship between specific surface area and pore size in liquid nitrogen experiment.

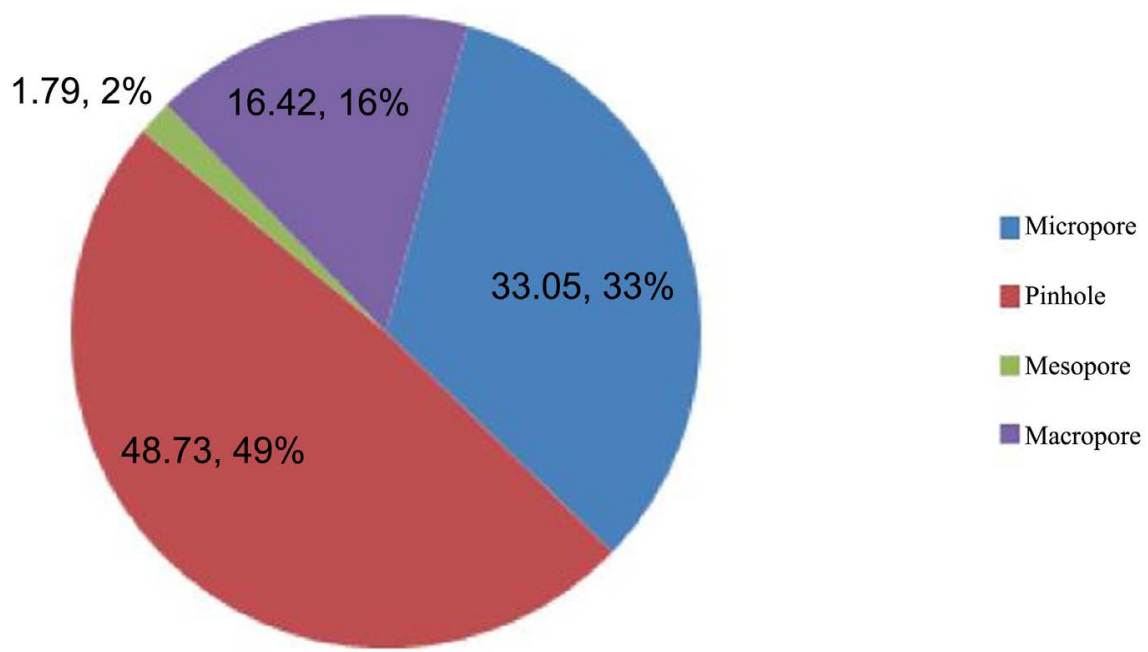

Figure 12. Mercury injection liquid nitrogen data combined with Pore volume percentage distribution.

in Taiyuan formation is between $84 \times 10^{-4} \mathrm{~cm}^{3} / \mathrm{g}$ and $134 \times 10^{-4} \mathrm{~cm}^{3} / \mathrm{g}$, with an average of $106.71 \times 10^{-4} \mathrm{~cm}^{3} / \mathrm{g}$. Among them, the main ones are micropores and small pores. The micropore volume accounts for $33.05 \%$ of the total pore volume, and the small pore volume accounts for $48.73 \%$ of the total pore volume. Macropores also had a certain development, accounting for $16.42 \%$, with the least development, accounting for only $1.79 \%$. The results show that micropores are mainly developed in the shale of Taiyuan formation, and the mesopores are 
not well developed.

Figure 13 is a plot of the pore volume and pore size of mercury injection liquid nitrogen, with the combined portion at $50 \mathrm{~nm}$. It can also be seen that each plot has a mutation at $50 \mathrm{~nm}$, the results show that the accuracy of liquid nitrogen and mercury injection test for shale pore measurement at about $50 \mathrm{~nm}$ is not the same, and further study is needed. In addition, Figure 12 also shows a peak in the range of $10-100 \mathrm{~nm}$, indicating that the pore volume at $10-100 \mathrm{~nm}$ is more developed than other parts.

2) Characterization of specific surface area of Taiyuan Formation Shale by low temperature nitrogen method and mercury injection method

From Table 3, it can be seen that the distribution of specific surface area of shale pores in Taiyuan formation is between $3032 \times 10^{-3} \mathrm{~m}^{2} / \mathrm{g}$ and $9017 \times 10^{-3}$ $\mathrm{m}^{2} / \mathrm{g}$, with an average of $5083 \times 10^{-3} \mathrm{~m}^{2} / \mathrm{g}$. As shown in Figure 14, the specific

Table 2. Mercury intrusion, liquid nitrogen and Pore volume data of the Taiyuan formation shale in the Qinshui basin.

\begin{tabular}{cccccccccc}
\hline & \multicolumn{4}{c}{ Pore volume $\left(10^{-4} \mathrm{~cm}^{3} / \mathrm{g}\right)$} & \multicolumn{5}{c}{ Pore volume ratio (\%) } \\
\cline { 2 - 5 } NUMBER & V1 & V2 & V3 & V4 & $\begin{array}{c}\text { Vt } \\
\text { Bribing }\end{array}$ & V1/Vt & V2/Vt & V3/Vt & V4/Vt \\
\hline HSM-29 & 21 & 50 & 7 & 10 & 88 & 23.86 & 56.82 & 7.95 & 11.36 \\
HSM-37 & 40 & 63 & 0 & 9 & 112 & 35.71 & 56.25 & 0.00 & 8.03 \\
HSM-58 & 21 & 18 & 1 & 44 & 84 & 25.00 & 21.43 & 1.19 & 52.38 \\
SH-20 & 32 & 55 & 2 & 15 & 104 & 30.77 & 52.88 & 1.92 & 14.42 \\
SH-35 & 70 & 39 & 0 & 15 & 124 & 56.45 & 31.45 & 0.00 & 12.10 \\
SH-45 & 44 & 75 & 2 & 13 & 134 & 32.84 & 55.97 & 1.49 & 9.70 \\
ST-15 & 27 & 67 & 0 & 7 & 101 & 26.73 & 66.33 & 0 & 6.93 \\
MEAN VALUE & 36.43 & 52.43 & 1.71 & 16.14 & 106.71 & 33.05 & 48.73 & 1.79 & 16.42 \\
\hline
\end{tabular}

Table 3. Mercury injection liquid nitrogen bound specific surface area data of Taiyuan formation shale in Qinshui basin.

\begin{tabular}{cccccccccc}
\hline \multirow{2}{*}{$\begin{array}{c}\text { SAMPLE } \\
\text { NUMBER }\end{array}$} & \multicolumn{7}{c}{ Pore specific surface area $\left(10^{-3} \mathrm{M}^{2} / \mathrm{g}\right)$} & \multicolumn{3}{c}{ Pore specific surface area ratio (\%) } \\
\cline { 2 - 10 } & V2 & V3 & V4 & $\begin{array}{r}\text { Vt } \\
\text { Bribing }\end{array}$ & V1/Vt & V2/Vt & V3/Vt & V4/Vt \\
\hline HSM-29 & 2120 & 965 & 12 & 1 & 3098 & 68.45 & 31.16 & 0.39 & 0.03 \\
HSM-37 & 4332 & 1286 & 4 & 1 & 5623 & 77.05 & 22.87 & 0.07 & 0.02 \\
HSM-58 & 2636 & 388 & 6 & 2 & 3032 & 87.00 & 12.81 & 0.20 & 0.07 \\
SH-20 & 3321 & 1098 & 6 & 1 & 4426 & 75.05 & 24.81 & 0.14 & 0.02 \\
SH-35 & 8120 & 896 & 1 & 1 & 9017 & 90.05 & 9.94 & 0.01 & 0.01 \\
SH-45 & 4670 & 1531 & 10 & 1 & 6212 & 75.19 & 24.64 & 0.16 & 0.02 \\
ST-15 & 2904 & 1219 & 5 & 1 & 4128 & 70.35 & 29.53 & 0.12 & 0.02 \\
MEAN VALUE & 4014.71 & 1054.71 & 6.28 & 1.33 & 5083 & 77.59 & 22.25 & 0.15 & 0.03 \\
\hline
\end{tabular}




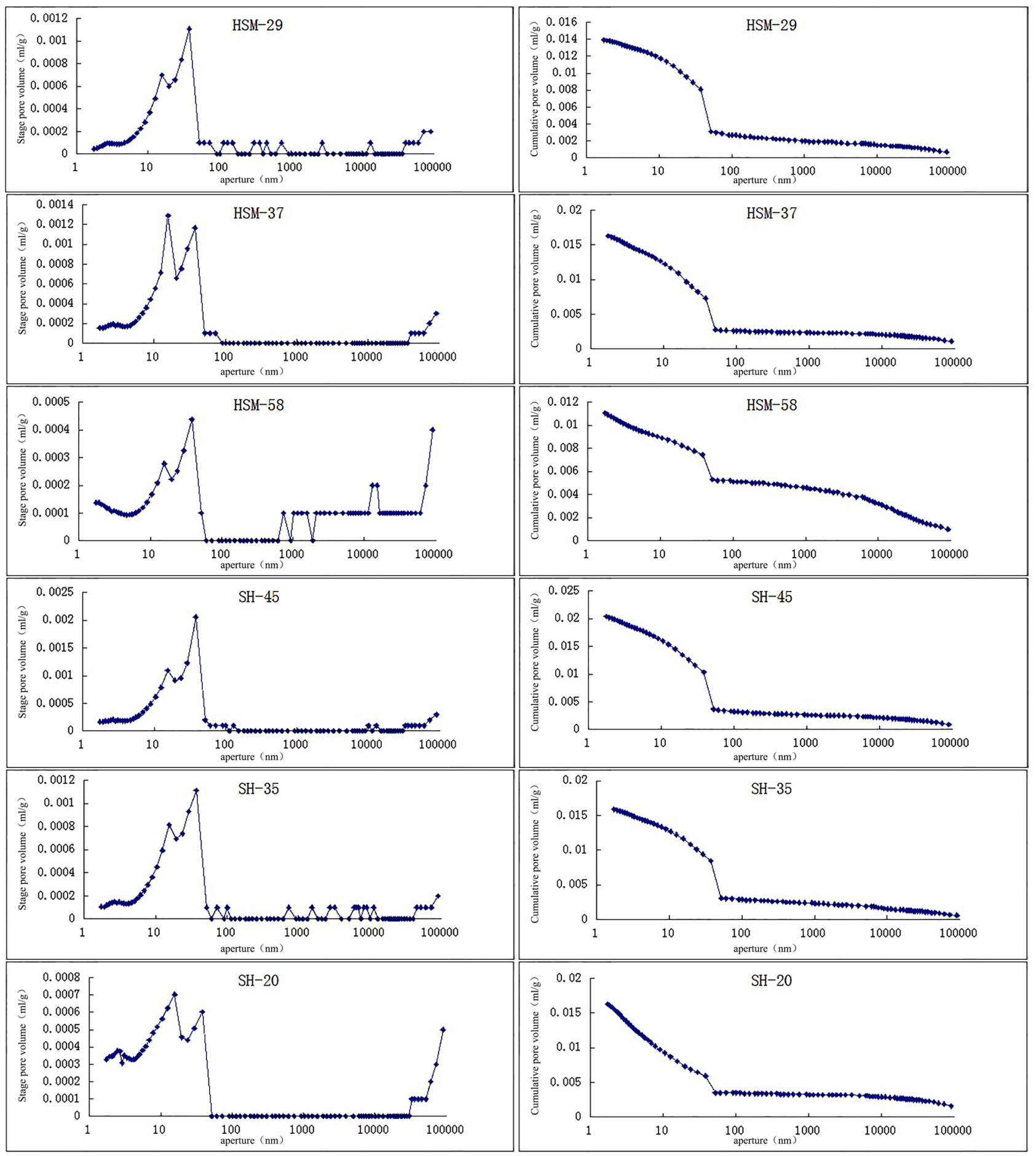

Figure 13. Relationship between pore volume and pore diameter in the combined stage of mercury injection experiment with liquid nitrogen.

surface area of micropores is $77.59 \%$, and that of micropores is $22.25 \%$. The combined contribution of micropores and micropores is $99.84 \%$, almost all of them. Fully reflected in the shale micro, small contribution to shale gas adsorption. The mercury intrusion into liquid nitrogen combined with specific surface area distribution as Figure 15. 


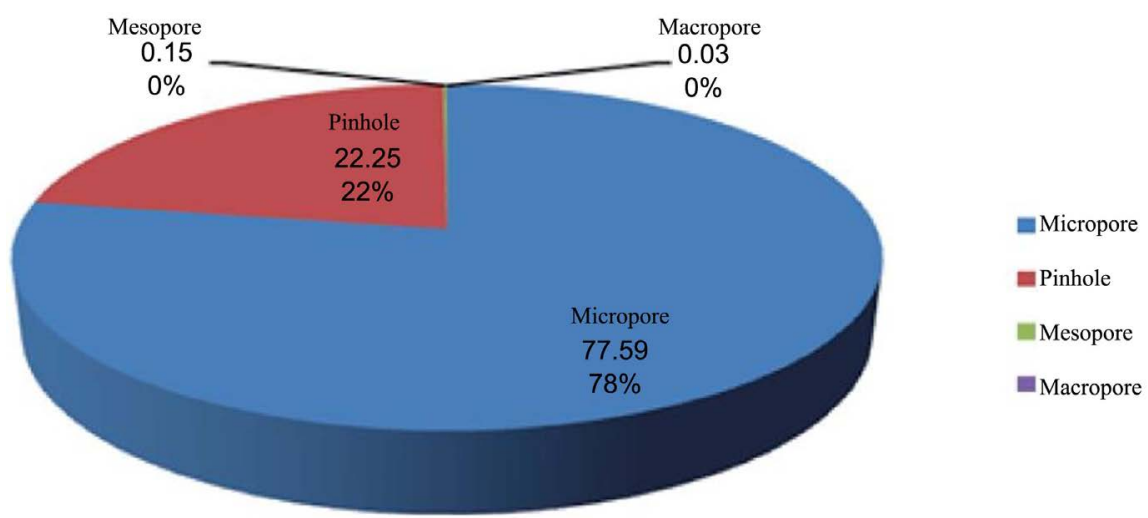

Figure 14. Mercury intrusion into liquid nitrogen combined with percentage distribution of specific surface area.

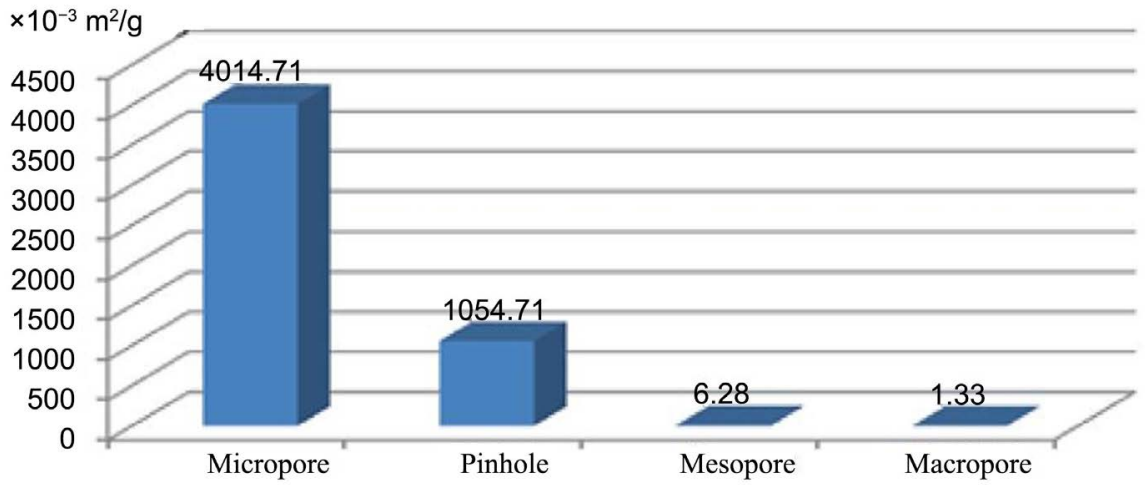

Figure 15. Mercury intrusion into liquid nitrogen combined with specific surface area distribution.

Figure 16 also shows a sudden change in the specific surface area of the shale pore at $50 \mathrm{~nm}$, indicating that the accuracy of the measurement of the shale pore at $50 \mathrm{~nm}$ is different from that of the liquid nitrogen and mercury injection experiments. Further study is needed. The stage specific surface area is very small above $100 \mathrm{~nm}$ and rapidly rises from $100 \mathrm{~nm}$ down, and has a peak at about 20 $\mathrm{nm}$. The pores of the Taiyuan Group Shale are more developed at about $20 \mathrm{~nm}$, and the accumulative specific surface area also rises rapidly below $100 \mathrm{~nm}$, it also shows that the specific surface of Taiyuan Formation Shale is mainly contributed by micro-pores.

\section{Relationship between Pore Structure and Shale Gas Accumulation of Taiyuan Formation in Qinshui Basin}

Shale gas accumulation needs some necessary conditions, including shale thickness, organic matter abundance (TOC), kerogen type, maturity (Ro), shale composition, permeability and so on. The thickness of Shale, organic matter abundance (TOC), kerogen type, maturity (Ro) and so on are the material basis of shale gas production, but after the formation of shale gas, a better reservoir space and migration channel are needed, in this way, shale gas can be better preserved and 


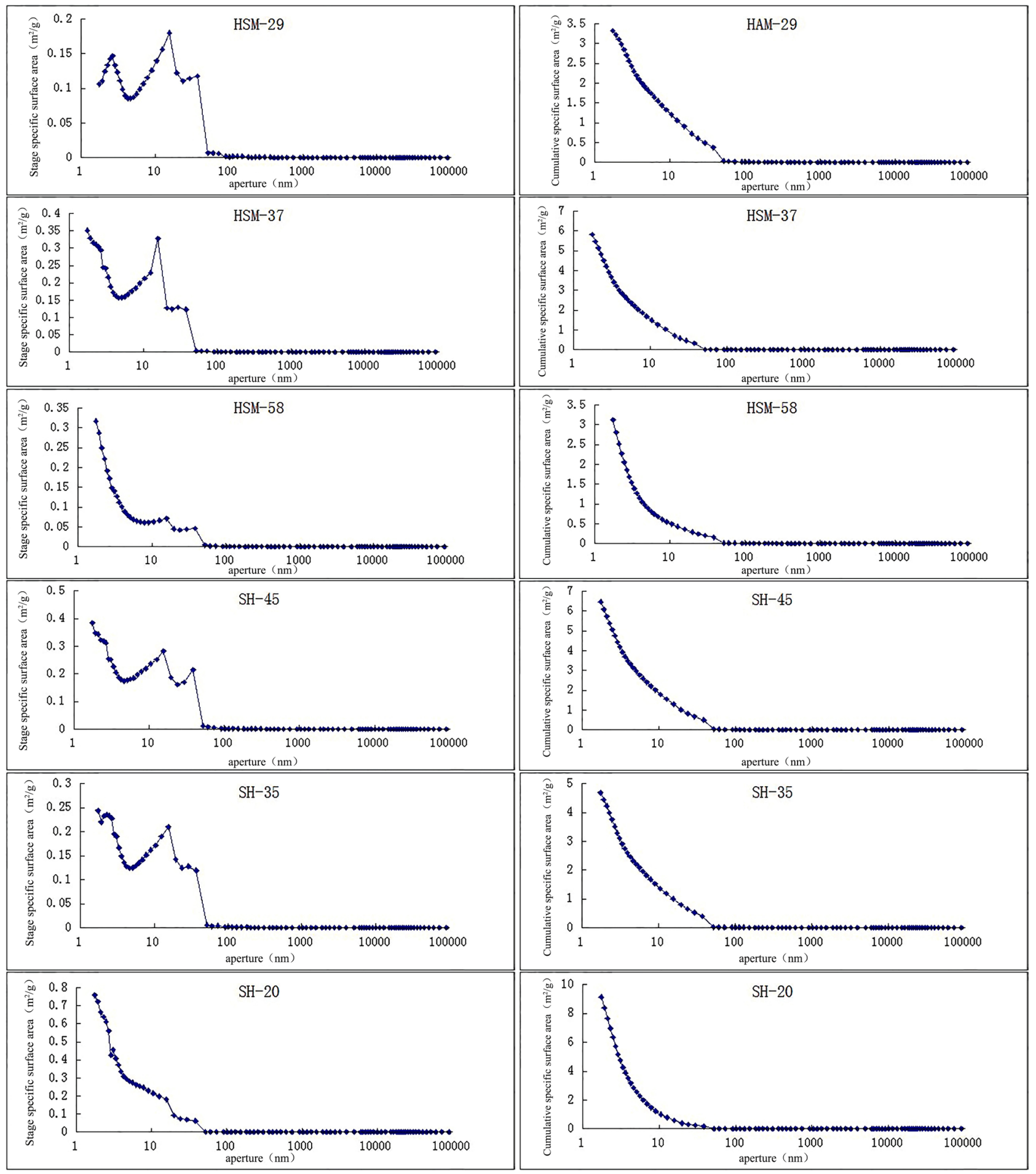

Figure 16. Relationship between pore size and specific surface area of liquid nitrogen in mercury injection stage.

developed later. The Pore structure of shale reservoir has a great influence on the accumulation and migration of shale gas, so the pore structure of shale reservoir is of great significance to the formation of shale gas.

Shale gas reservoir is a typical low porosity and low permeability reservoir. Because of the narrow micropore channel, the adsorption energy of shale gas re- 
servoir is higher than that of Macropore, so the interaction between shale pore surface and adsorbate is stronger and more gas can be adsorbed. Therefore, the effect of porosity in shale on shale gas accumulation is essentially the effect on shale gas storage capacity. In the pores of less than $2 \mathrm{~nm}$, methane molecules are in the adsorption state because of insufficient movement space and force field of Pore Wall, and methane molecules do not move in the pores until the pore diameter reaches $50 \mathrm{~nm}$, therefore, the importance of nano-porosity to shale gas reservoir can be seen.

According to the research of Chen Shangbin (Zhang et al., 2008), the nano-pores in the shale reservoir of Longmaxi formation in south Sichuan are mainly distributed between 2 - $40 \mathrm{~nm}$, accounting for $88.39 \%$ of the total pore volume and $98.85 \%$ of the total surface area. The Pore volume of the Qinshui basin is $75.37 \%$ of the total pore volume and $86.54 \%$ of the total surface area, but it is mainly distributed between $2 \mathrm{~nm}$ and $40 \mathrm{~nm}$. In this respect, the pore structure of the Taiyuan Formation Shale is favorable for shale gas accumulation. But the total pore volume of Taiyuan Formation Shale is only $106.71 \times 10^{-4} \mathrm{~cm}^{3} / \mathrm{g}$ on average, which is only about $40 \%$ of Longmaxi formation in south Sichuan, and the total specific surface area is only $5.083 \mathrm{~m}^{2} / \mathrm{g}$, which is only about $30 \%$ of Longmaxi formation in south Sichuan, compared with Longmaxi formation in south Sichuan, Taiyuan Formation Shale is poor. But Taiyuan formation is different from Longmaxi formation. It is a marine-continental transitional shale reservoir with multiple layers of siltstone interbedded in the shale. Because of its proximity to the shale and low permeability, it can also be a good reservoir, contribute to the storage of shale gas. In this respect, the Taiyuan Formation Shale reservoir in Qinshui basin is better than Longmaxi formation in south Sichuan. In addition, according to the experimental study of liquid nitrogen and mercury injection, the pores in Taiyuan formation are mainly open pores, which is beneficial to pressure difference transfer, can improve the efficiency of shale gas resolution, and provide a channel for Shale gas migration, favorable for shale gas development.

\section{Conclusion}

Taking the shale of Taiyuan Formation in Qinshui Basin as the research object, the study analyzed the pore size of the shale of Taiyuan formation in detail from micropore to macropore by the methods of mercury injection, liquid nitrogen analysis and combination of liquid nitrogen and mercury injection.

1) the mercury injection test shows that the visible pores and macropores are poorly developed and distributed unevenly in the shale of Taiyuan formation, and the micropores are well developed in the shale, and there are more open pores in the pore diameter range, and the pore connectivity is good;

2) the liquid nitrogen experiment shows that the pores of Taiyuan Shale are relatively developed between $15 \mathrm{~nm}$ and $20 \mathrm{~nm}$, and the formation of hysteresis loop may be caused by some narrow slit pores with similar layered structure; 
3) the comprehensive analysis of liquid nitrogen and mercury injection experiments show that the shale of the Taiyuan formation mainly develops micropores, the Mesopores is not developed, the pore volume at $10-100 \mathrm{~nm}$ is more developed than other parts, and the specific surface is mainly contributed by micropores, which can improve the efficiency of shale gas resolution; at the same time, it provides a channel for Shale gas migration, which is beneficial to the development of shale gas.

\section{Conflicts of Interest}

The authors declare no conflicts of interest regarding the publication of this paper.

\section{References}

Chen, S. B., Zhu, Y. M., Wang, H. Y. et al. (2012). Characteristics of Nano-Pore Structure of Longmaxi Formation Shale Gas Reservoir in Southern Sichuan Basin and Its Significance for Hydrocarbon Accumulation. Journal of Coal, No. 3, 438-444.

Chen, Y. J. (2013). The Main Control Factors of CBM Enrichment in Southern Qinshui Basin and the Optimization of Enrichment Block. Jingzhou: Yangtze University.

Clarkson, C. R., Solano, N., Bustin, R. M. et al. (2012). Pore Structure Characterization of North American Shale Gas Reservoirs Using USANS/SANS, Gas Adsorption, and Mercury Intrusion. Fuel, 103, 606-616. https://doi.org/10.1016/j.fuel.2012.06.119

Cui, J. W., Zou, C. N., Zhu, R. K. et al. (2012). New Progress of Shale Porosity Research. Advances in Earth Science, 12, 1319-1325.

Curtis, J. B. (2002). Fractured Shale-Gas Systems. AAPG Bulletin, 86, 1921-1938. https://doi.org/10.1306/61EEDDBE-173E-11D7-8645000102C1865D

Gu, J. Y., Ye, J. P., \& Fang, C. (2011). Prospects for Shale Gas Resources in the Qinshui Basin Conference Paper Something. In CBM Symposium.

Jia, Y. H., Lu, A. L., Tian, H. L. et al. (2012). Study on Favorable CBM Exploitation Block in Qinshui Basin, Shanxi Province. China Mining, No. 3, 38-41.

Jiang, F. J., Pang, X. Q., Ouyang, X. C. et al. (2012). General Situation of Shale Gas Research in the World and Potential Analysis of Shale Gas Resources in China. Geoscience Frontiers, No. 2, 198-211.

Li, J. Z., Dong, D. Z., Chen, G. S. et al. (2009). Prospect and Strategic Position of Shale Gas Resources in China. Natural Gas Industry, No. 5, 11-16 + 134.

Liu, H. J., Qin, Y., Sang, S. X. et al. (1998). Geology of Coalbed Methane in Southern Shanxi, China. Taiyuan: University Press.

Liu, H. L., Wang, H. Y., Liu, R. H. et al. (2010). Shale Gas Resources and Their Exploration Potential in China. Journal of Geology, No. 9, 1374-1378.

Ma, W. G., Wang, Y., Hai, M. Y. et al. (2013). Study on Pore Structure Characteristics of Core by Mercury Injection Method. Laboratory Technology and Management, No. 1, 66-69.

Pu, B. L. (2008). Analysis of Reservoir Forming Conditions of Shale Gas in Sichuan Basin. Qingdao: China University of Petroleum.

Tian, H., Zhang, S. C., \& Liu, S. B. (2012). Characteristics of Organic-Rich Shale Studied by Mercury Injection and Gas Adsorption Methods. Journal of Petroleum Sciences, No. 3, 419-427. 
Wang, G. L. (2005). Structure of Energy Basin in North China. Xuzhou: China Mining University Press.

Wang, L. P. (2012). Prospect of Shale Gas Exploration in Shanxi Formation of Qinshui Basin. Petrochemical Applications, 12, 1-3 + 14 .

Wang, Y., Feng, F. C., Mao, Y. B. et al. (1998). An Analysis of the Tectonic Conditions for CBM Occurrence at the Southern End of the Qinshui Basin. New Geology, No. 3, 28-31.

Xie, X. Y., Tang, H. M., Wang, C. H. et al. (2006). Comparison of Nitrogen Adsorption Method and Mercury Injection Method in Measuring Pore Size Distribution of Mud Shale. Natural Gas Industry, 12, 100-102 + 202-203.

Yang, F., Ning, Z. F., Kong, D. T. et al. (2013). Analysis of Pore Structure of Shale by High Pressure Mercury Method and Nitrogen Adsorption Method. Natural Gas Geoscience, No. 3, 450-455.

Yu, B. S. (2013). Pore Classification and Characterization of Shale Gas Reservoir. Geoscience Frontiers, No. 4, 211-220.

Zhang, J. C., Xu, B., Nie, H. K. et al. (2008). Exploration Potential of Shale Gas Resources in China. Natural Gas Industry, No. 6, 136-140 + 159-160.

Zhao, J. Z., Fang, C. Q., Zhang, J. et al. (2011). Evaluation of Selected Shale Gas Areas in China from the Perspective of North American Shale Gas Exploration and Development. Proceedings of the Xi'an Shiyou University, No. 2, 1-7 + 110 + 117 . 